\title{
Optimizing Pharmacy Learner Rotations to Improve Clinical Productivity: A Study to Assess 3 Pharmacy Layered Learning Practice Models in an Inpatient Tertiary Care Oncology Unit
}

\author{
Lauren (Ellie) Salsbury, Stephanie Lovering, Tiffany Nguyen, Jason Yung, and Jason Wentzell
}

Can J Hosp Pharm. 2021;74(3):282-90

DOI: 10.4212/cjhp.v74i3.3156

\section{INTRODUCTION}

The provision of quality experiential learning is an imperative component of pharmacy education. ${ }^{1}$ However, some academic pharmacy programs and institutional pharmacy departments may find the growing demand for experiential education rotations difficult to accommodate. ${ }^{2}$ The layered learning practice model (LLPM) is a practice structure that can facilitate the accommodation and incorporation of more learners into a given practice site during academic rotations. Within the pharmacy context, the LLPM structure could emulate that of a common medicine-based teaching and practice environment and would consist of staff pharmacists, pharmacy residents, and pharmacy students. ${ }^{3}$

Within the LLPM, direct patient care activities are delegated to students, both to impart more clinical responsibility and to encourage near-peer learning and development as clinical pharmacists. ${ }^{4}$ The pharmacy residents gain supervised opportunities to act as preceptors for junior learners in a safe environment, in addition to providing direct patient care themselves, which encourages their further development as independent practitioners. ${ }^{5}$ One or more staff pharmacist preceptors coordinate and facilitate the activities of the group and are responsible for completed interventions and ultimately the care delivered by the pharmacy residents and students. ${ }^{4}$ While ensuring that learners meet their educational requirements, the presence of students should not compromise clinical services or productivity. ${ }^{6}$ The positive impact of LLPMs involving pharmacy learners has been demonstrated previously. Those earlier studies found improvement in resolution of medication-related problems, patient education, and patient satisfaction scores. ${ }^{7-9}$

Evaluating the clinical productivity of pharmacists using standardized performance indicators is encouraged to yield generalizable and reproducible performance results, which are ultimately used as a basis for clinical service or operational decisions. Using a modified Delphi process, a Canadian working group of pharmacy leaders and hospital pharmacists developed a list of 8 consensus-based clinical pharmacy key performance indicators (cpKPIs) (Table 1), which are supported by the Canadian Society of Hospital Pharmacists (CSHP). ${ }^{10-13}$

Yung and others ${ }^{14}$ were the first to assess the impact of an LLPM on clinical productivity through quantification of the CSHP cpKPIs across a spectrum of LLPM scenarios. Their study demonstrated that the structured LLPM, comprising pharmacists, pharmacy residents, and pharmacy students in an inpatient oncology unit, did not impair the delivery of pharmaceutical care relative to standard practice, as measured by the cpKPIs. The study compared the following 3 scenarios: pharmacists alone; pharmacists and pharmacy students; and pharmacists, pharmacy residents, and pharmacy students. The scenarios had comparable total numbers of cpKPIs standardized to 20 pharmacist workdays. Although the total number of cpKPIs was similar across scenarios, there was a trend toward a reduction in discharge medication reconciliation and patient education at discharge when pharmacy learners were present. It was hypothesized that this trend was due to the occurrence of daily afternoon academic debriefing and patient review sessions, which took place at a time when many patients are discharged.

Yung and others ${ }^{14}$ showed that it is possible to maintain clinical efficiency while offering pharmacy learner rotations within an LLPM structure. Although maintenance of clinical efficiency is an acceptable outcome, the next logical step is to attempt to improve the clinical capacity of pharmaceutical care delivery by optimizing the structure and performance of activities within the LLPM. The current study aimed to improve the cpKPIs of discharge medication reconciliation and patient education at discharge by involving Doctor of Pharmacy (PharmD) students in the role of medication 
TABLE 1. Canadian Consensus Clinical Pharmacy Key Performance Indicators (cpKPIs) and Definitions ${ }^{a}$

cPKPI

1. Medication reconciliation on admission

2. Pharmaceutical care plan

3. Drug therapy problems (DTPs)

4. Interprofessional patient care rounds

5. Patient education during hospital stay

6. Patient education at discharge

7. Medication reconciliation at discharge

8. Bundled patient care interventions

\section{Definition}

Proportion of patients who received documented medication reconciliation on admission (and had resolution of identified discrepancies), performed by a pharmacist

Proportion of patients for whom a pharmacist has developed and initiated a pharmaceutical care plan

Number of DTPs resolved by a pharmacist per admission

Proportion of patients for whom a pharmacist participated in interprofessional patient care rounds to improve medication management

Proportion of patients who received education from a pharmacist about their disease(s) and medication(s) during their hospital stay

Proportion of patients who received medication education from a pharmacist at discharge

Proportion of patients who received documented medication reconciliation at discharge (and had resolution of identified discrepancies), performed by a pharmacist

Proportion of patients who received bundled care by a pharmacist as defined by the following criteria:

- Medication reconciliation on admission

- Pharmaceutical care plan AND/OR resolution of DTPS

- Pharmacist's participation in interprofessional patient care rounds

- Patient education during hospital stay AND/OR at discharge

- Medication reconciliation at discharge

aAdapted, with permission of the Canadian cpKPI Collaborative, from Canadian Consensus on Clinical Pharmacy Key Performance Indicators: Knowledge Mobilization Guide. ${ }^{10}$

safety facilitators at hospital discharge and assigning them to work with the health team to complete these discharge activities. This role involved performing the steps in the checklist for medication safety at transitions, developed by the Institute for Safe Medication Practices Canada (ISMP Canada). ${ }^{15}$

A principal question that this study aimed to address was how to structure an LLPM to optimize capacity for care delivery, as measured by cpKPIs. Three distinct 8 -week LLPM rotations were designed to provide insight into this question. The model was similar to that of the previous study, with pharmacists, residents, and students in various combinations; however, the number of pharmacy students $(2,3$, or 4$)$ was varied across 3 intervention groups (termed "blocks"). By modifying the number of students involved, we explored whether there is an optimal number of students within an LLPM that represents a practical balance between the preceptor's time and other workplace responsibilities and the students' clinical contributions to patient care.

This study advances the exploratory research completed by Yung and others ${ }^{14}$ to help identify strategies to optimize structured experiential learning and may guide the clinical teaching and role assignment associated with pharmacylearner rotations. Additionally, the patient care contributions of each pharmacy professional were measured through quantification of completed cpKPI-related activities, which elucidated areas that may require emphasis in the design of future rotations to ensure a balanced clinical experience.
The primary objective of the current study was to determine and compare the percentage of all eligible cpKPIrelated activities completed for patients between intervention groups and standard practice. In addition, the study had 4 secondary objectives: to determine the percentage of eligible patients receiving care related to 6 of the cpKPIs and to compare these proportions between intervention groups and standard practice; to compare the number of drug therapy problems (DTPs) resolved per patient between intervention groups and standard practice; to compare the total number of cpKPIs, standardized to 20 pharmacist workdays, between intervention groups and standard practice; and to describe the contributions of each pharmacy professional to pharmaceutical care, as measured by cpKPIs.

\section{METHODS}

This retrospective quality assurance study assessed a pharmacy practice intervention that took place over a 6-month period, from March 7 to August 20, 2018, corresponding to 3 planned 8-week PharmD student rotation blocks. The study setting was an inpatient medical oncology unit in The Ottawa Hospital in Ottawa, Ontario. The unit had 35 to 40 dedicated medical oncology beds throughout the study period. At the time of the study, the hospital was using a paper-based charting system. The study was approved by the institution's research ethics board. 
Study participants consisted of 2 full-time equivalent (FTE) oncology pharmacists (J.W., S.L.), 3 pharmacy residents (including J.Y.), and 8 PharmD students organized in 3 LLPMs. Each LLPM was composed of the 2 pharmacists, one of the residents, and 2, 3, or 4 students (with one of the students spanning 2 rotations) (Table 2 ). All of the residents were licensed pharmacists during the period of the study. The 2 pharmacists were experienced residency and pharmacy student preceptors and had previously been involved in LLPM rotations at the same institution. ${ }^{14}$ Comparator data were collected from a nonconsecutive 10-week period, including 7 weeks of data previously collected by Yung and others ${ }^{14}$ (September 5 to 15, 2017, and January 8 to February 9, 2018) with an extension of 3 weeks (February 12 to March 2, 2018) before the intervention periods. This extension of the comparator period was intended to improve data robustness, with data from the extension being combined with data from the original period using dataset totals. These collective data were representative of the standard practice of the 2 FTE pharmacists without learners present.

The roles and scopes of practice of students, residents, and pharmacists in this study reflected those described previously. ${ }^{7-9}$ Learners were incorporated within the oncology practice, providing direct patient care on the unit, and were also given suitable access to office computers and workspaces.

The PharmD students provided longitudinal patient care for 2 to 5 patients at a time. They also alternated in fulfilling the additional responsibility of facilitating patient discharges, whereby the assigned student carried a "discharge pager" and was notified when patients were ready for discharge, at which time patient education and medication reconciliation were to be performed. On their first day before the data collection period, the students underwent a 1-hour training session with their preceptors on the use of the ISMP Canada checklist for medication safety at transitions. ${ }^{15} \mathrm{Com}-$ pletion of the checklist indicated fulfilment of the cpKPIs for patient education at discharge and medication reconciliation at discharge. If the assigned PharmD student was unavailable at the time of a patient's discharge, a resident or pharmacist would perform these activities.

The residents provided care to 3 to 6 patients at a time while also providing direct instruction to the students, facilitating debriefing sessions, and teaching. The oncology pharmacists carried out the roles of supervisor and teacher. In addition to their distribution and clinical practices, they coordinated the activities of the team, modelled patient care duties for learners, conducted therapeutic discussions, and facilitated debriefing sessions for all learners. All of the learners practised within the scope of their authority and debriefed daily with preceptors to ask questions and review work. All orders placed in the paper-based charts were cosigned by one of the pharmacist preceptors. The pharmacists were responsible for all medication-related outcomes of the patients and participated in direct care activities for patients on the unit who were not assigned to a particular learner.

\section{Recording of cpKPIs}

All participating pharmacists, residents, and students underwent training to recognize and record the cpKPIs as defined by the CSHP consensus guidelines. ${ }^{10}$ Training consisted of a 1-hour presentation given by one of the study investigators (J.W.) on the first day of each rotation. This presentation was additional to the training described above for the student role of discharge facilitator. The training materials and procedures were similar to the process described by Yung and others. ${ }^{14}$ A concise instruction sheet and project manual were provided, which included examples of the DTPs (available as Appendix 2 of the previous article by Yung and others ${ }^{14}$ ). The data collection period started within the first day after completion of training.

The participants were given stickers that were colourcoded according to their role (student, resident, or pharmacist) and labelled from 1 to 7 , representing each of the cpKPIs investigated in this study (Table 3). Labels were attached to daily inpatient rosters adjacent to the patient who received the corresponding cpKPI-related care. The appropriate affixing of cpKPI labels was reviewed and

TABLE 2. Composition of Control and Intervention Groups

\begin{tabular}{lcccc} 
& \multicolumn{4}{c}{ Block No. and Dates ; No. of Persons (Duration of Participation) } \\
\cline { 2 - 5 } Role & Control & $\begin{array}{c}\text { Block } 1 \\
\text { March } 7 \text { to April } 27\end{array}$ & $\begin{array}{c}\text { Block } 2 \\
\text { April } 30 \text { to June } 22\end{array}$ & $\begin{array}{c}\text { Block } 3 \\
\text { June } 25 \text { to Aug } 20\end{array}$ \\
\hline $\begin{array}{lccc}\text { Pharmacist } \\
\text { Historical data } \\
(10 \text { weeks) }\end{array}$ & $n=2$ (8 weeks) & $n=2$ (8 weeks) & $n=2$ (8 weeks) \\
Pharmacy resident & NA & $n=1$ (5 weeks) & $n=1$ (5 weeks) & $n=1$ (5 weeks) \\
PharmD student & NA & $n=1$ (8 weeks) & $n=2$ (8 weeks) & $n=3(8$ weeks) \\
& $n=1$ (5 weeks) & $n=1$ (4 weeks) & $n=1(4$ weeks) \\
\hline
\end{tabular}

NA = not applicable, PharmD = Doctor of Pharmacy.

${ }^{a}$ All dates in calendar year 2018.

${ }^{b}$ Control group data were collected during 10 nonconsecutive weeks, including 7 weeks of data previously reported by Yung and others. ${ }^{14}$ 
TABLE 3. Additional Requirements for Sticker Documentation for Tracking Clinical Pharmacy Key

Performance Indicators (cpKPIs) on Patient Care Rosters

\begin{tabular}{|ll}
\hline cPKPI Label & \\
\hline 1. Admission medication reconciliation & - Reviewed the admission medication reconciliation \\
& - Identified and resolved discrepancies \\
\hline 2. Pharmaceutical care plan & None \\
\hline 3. Drug therapy problems (DTPs) & Reported type of DTP resolved by documenting an assigned letter on the label: \\
& A. Unnecessary drug therapy \\
& B. Requires additional drug therapy \\
& C. Inappropriate drug therapy \\
& D. Dose too low \\
& E. Dose too high \\
& F. Adverse drug reaction \\
4. Interprofessional patient care rounds & G. Inappropriate adherence \\
& - Attended bullet rounds \\
\hline 5. Patient education during hospital stay & None \\
\hline 6. Patient education at discharge & None \\
\hline 7. Discharge medication reconciliation & - Reviewed the discharge medication reconciliation \\
\hline
\end{tabular}

confirmed daily by the pharmacists, to ensure the accuracy and standardization of coding. For all patients, pharmacists were assumed to have participated in patient care rounds (cpKPI 4), since standard practice on the unit is to attend interprofessional bullet rounds.

Study participants generally worked from 0800 to 1600 on weekdays, and cpKPIs were recorded daily during these working clinical hours. At the study institution, the role of the pharmacist on evening and weekend shifts differs significantly from that of pharmacists working the daytime clinical shift; therefore, no study interventions were recorded in the evenings, on weekends, or on provincial holidays.

\section{Data Analysis}

Patient lists were collected and stored in a secure area in the pharmacy at the end of each week. The data were transcribed from patient rosters into a deidentified, password-protected quality assurance database (Excel version 1808, Microsoft Corporation) by one of the authors (L.S.).

The data collected were used to calculate the percentage of eligible cpKPI-related activities that were completed for patients in each of the 3 intervention periods (primary objective). To account for patients admitted across multiple study blocks, patients were considered ineligible for cpKPIs previously documented, with the exception of DTPs identified and resolved. Patients who died were not discharged and therefore were not considered eligible for assessment of education at discharge or medication reconciliation at discharge. Mean percentages were compared between intervention and control groups using $\chi^{2}$ statistical tests. The Student $t$ test was used to compare the number of DTPs resolved per patient. Overall productivity was assessed using total cpKPIs completed by a given group, standardized to 20 pharmacist workdays. Standardization helps to adjust for any practical differences in staffing or vacations that occurred across the 6-month study period, and 20 days was selected to represent approximately 1 month of pharmacist time. Total cpKPIs represent an absolute value and were used to account for unequal distribution of patient load between groups; these data are reported descriptively as well.

\section{RESULTS}

The results of this study were synthesized using data from 666 patient admissions over three 8-week intervention blocks between March 7 and August 20, 2018. Patient admission characteristics of the intervention groups can be found in Table 4. The total proportions of eligible cpKPIs completed for the standard practice (control) group and the 2-, 3-, and 4 -student blocks were $47 \%, 41 \%, 50 \%$, and $52 \%$, respectively (Table 5). The total proportion of patients receiving eligible cpKPI-related care with the 2-student model (block 1) was significantly lower than with the control group (absolute difference $6 \%, 95 \%$ confidence interval [CI] -9.3 to -2.7 ; $p<0.001$ ), suggesting reduced productivity with this LLPM relative to standard practice. In contrast, the total proportion of patients receiving eligible cpKPI-related care with the 4-student model (block 3 ) was significantly higher than with the control group (absolute difference 5\%, 95\% CI 1.8 to 8.2; $p=0.002$ ), indicating higher productivity with this model relative to pharmacists working alone. There was no significant difference between the 3-student model and standard 
TABLE 4. Baseline Characteristics of Patient Admissions during Study Blocks

\begin{tabular}{|c|c|c|c|}
\hline Characteristic & Block 1 & Block 2 & Block 3 \\
\hline $\begin{array}{l}\text { Duration of block (d) } \\
\text { [no. of workdays] }^{a}\end{array}$ & $51[74]$ & $53[67]$ & $56[65]$ \\
\hline No. of admissions & 205 & 223 & 238 \\
\hline $\begin{array}{l}\text { Patient age (years) } \\
\text { (mean } \pm \text { SD) }\end{array}$ & $63.0 \pm 13.4$ & $63.5 \pm 14.0$ & $63.0 \pm 15.0$ \\
\hline $\begin{array}{l}\text { Length of stay (days) } \\
\text { (mean } \pm \text { SD) }\end{array}$ & $16.2 \pm 20.3$ & $13.8 \pm 18.3$ & $12.1 \pm 14.3$ \\
\hline
\end{tabular}

$\mathrm{SD}=$ standard deviation

aThe number of workdays refers to the number of days worked by pharmacists during the period of the block. This number takes into account the Monday-to-Friday work week of the 2 full-time pharmacists.

practice, although there was a trend toward higher productivity (absolute difference $3 \%, 95 \%$ CI -0.2 to $6.2 ; p=0.07$ ).

The results for proportions of patients in each block receiving each type of cpKPI-related care (compared with standard practice) are presented in Table 6 and depicted in Figure 1. Significantly higher proportions of patients received a pharmaceutical care plan and education during their admission with the 4-student model (block 3) than with standard practice. The absolute differences were $16 \%$ (95\% CI 8 to $24 ; p<0.001)$ and $20 \%(95 \%$ CI 12 to 27 ; $p<0.001)$, respectively.

The results for education at discharge and discharge medication reconciliation were more variable (Table 6). A
TABLE 5. Total Proportions of Eligible Clinical Pharmacy Key Performance Indicators Completed for Patients in Each Block, Relative to Standard Practice (Control)

\begin{tabular}{lcccc} 
Study Block & $\begin{array}{c}\text { Total } \\
\text { Proportion } \\
\text { Completed (\%) }\end{array}$ & $\begin{array}{c}\text { Absolute } \\
\% \text { Difference } \\
(95 \% \text { Cl) }\end{array}$ & $\boldsymbol{p}$ Value \\
\hline Control & 47 & NA & NA \\
\hline $\begin{array}{l}\text { Block 1 } \\
\text { (2 students) }\end{array}$ & 41 & -6 & $(-9.3$ to -2.7$)$ & $<0.001$ \\
$\begin{array}{l}\text { Block 2 } \\
\text { (3 students) }\end{array}$ & 50 & 3 & $(-0.2$ to 6.2) & 0.07 \\
\hline $\begin{array}{l}\text { Block 3 } \\
\text { (4 students) }\end{array}$ & 52 & 5 & $(1.8$ to 8.2) & 0.002 \\
\hline
\end{tabular}

$\mathrm{Cl}=$ confidence interval, $\mathrm{NA}=$ not applicable.

significantly higher proportion of patients received education at discharge with the 3-student model (block 2; absolute difference 9\%, 95\% CI 2 to $17 ; p=0.016$ ), and there was a trend toward higher productivity with the 4-student model (block 3). Significantly smaller proportions of eligible patients received medication reconciliation at discharge with the 2- and 4-student models (blocks 1 and 3, respectively), with no difference observed with the 3 -student model (block 2).

The average number of DTPs resolved per eligible patient were calculated and compared between intervention and control groups (Table 7). There was a statistically significant reduction in mean DTPs resolved per patient with the

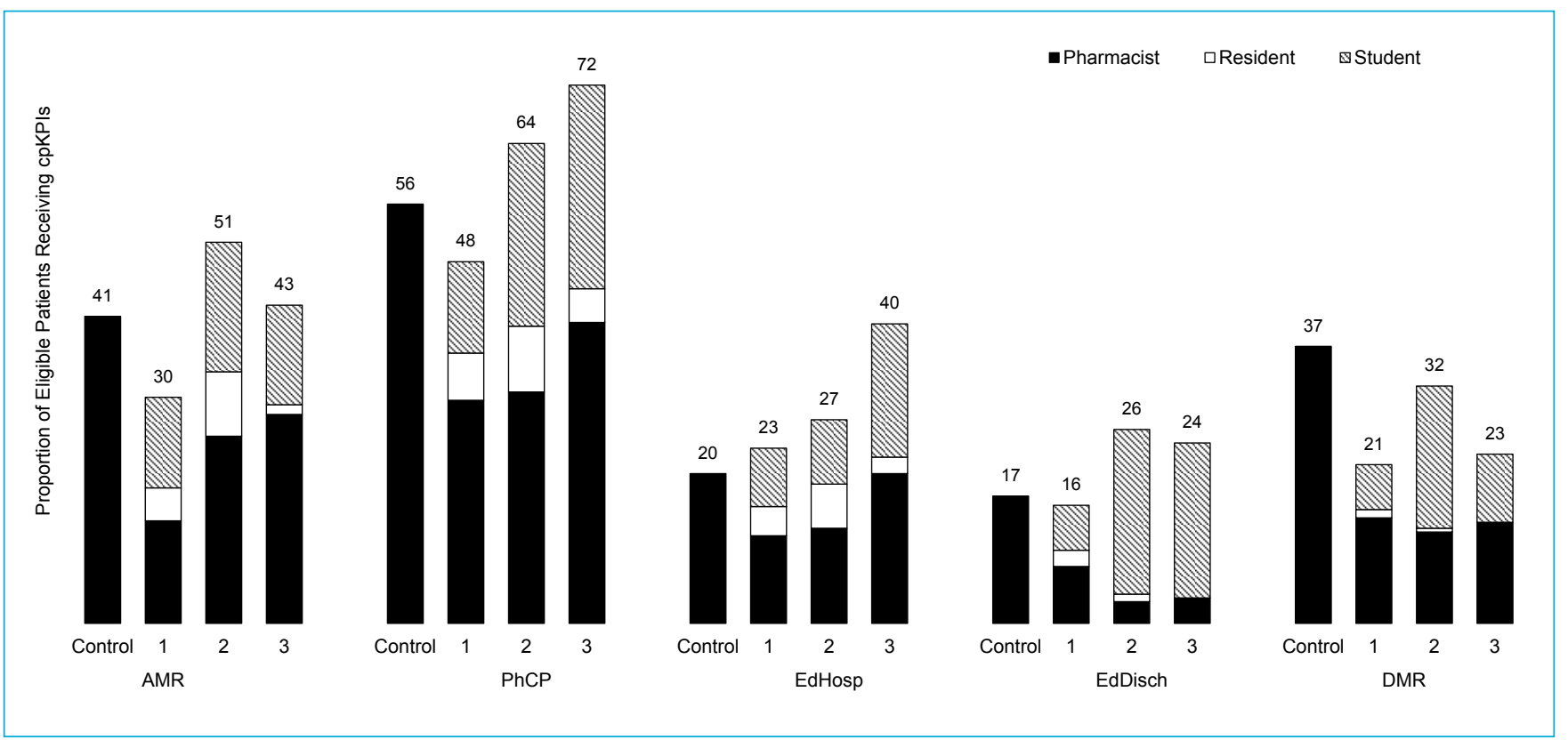

FIGURE 1. Proportion of eligible patients receiving care associated with clinical pharmacy key performance indicators (cpKPIs) for each intervention group (block) and standard practice (control), by type of cpKPI. The numbers 1, 2, and 3 designate blocks 1, 2, and 3, respectively, where blocks were distinguished by the number of PharmD students. AMR = admission medication reconciliation, DMR $=$ discharge medication reconciliation, EdDisch = patient education at discharge, EdHosp = patient education during hospital stay, PhCP = pharmaceutical care plan . 
TABLE 6. Proportions of Eligible cpKPIs Completed for Patients in Each Block, Relative to Standard Practice

\begin{tabular}{|c|c|c|c|}
\hline \multirow[b]{2}{*}{ сpKPI } & \multicolumn{3}{|c|}{ Block No.; \% Difference ${ }^{a}(95 \% \mathrm{Cl})$} \\
\hline & Block 1 & Block 2 & Block 3 \\
\hline 1. Admission medication reconciliation & $\begin{array}{c}-11 \quad(-19 \text { to }-3) \\
p=0.01\end{array}$ & $\begin{array}{c}10 \text { (6 to } 23) \\
p<0.001\end{array}$ & $\begin{array}{c}1 \text { ( }-7 \text { to } 9) \\
p=0.81\end{array}$ \\
\hline 2. Pharmaceutical care plan & $\begin{array}{c}-8(-17 \text { to } 1) \\
p=0.073\end{array}$ & $\begin{array}{c}8(-1 \text { to } 16) \\
p=0.064\end{array}$ & $\begin{array}{c}16(8 \text { to } 24) \\
p<0.001\end{array}$ \\
\hline 3. Drug therapy problems & $\begin{array}{c}-8(-16 \text { to } 1) \\
p=0.066\end{array}$ & $\begin{array}{c}-6(-14 \text { to } 2) \\
p=0.16\end{array}$ & $\begin{array}{c}-2(-10 \text { to } 6) \\
p=0.63\end{array}$ \\
\hline 5. Patient education during hospital stay & $\begin{array}{c}3(-4 \text { to } 10) \\
p=0.4\end{array}$ & $\begin{array}{c}7(0 \text { to } 14) \\
p=0.05\end{array}$ & $\begin{array}{c}20 \text { (12 to } 27) \\
p<0.001\end{array}$ \\
\hline 6. Patient education at discharge & $\begin{array}{c}-1(-8 \text { to } 6) \\
p=0.78\end{array}$ & $\begin{array}{l}9 \text { (2 to } 17) \\
p=0.016\end{array}$ & $\begin{array}{l}7(0 \text { to } 14) \\
p=0.057\end{array}$ \\
\hline 7. Discharge medication reconciliation & $\begin{array}{c}-16(-24 \text { to }-8) \\
p<0.001\end{array}$ & $\begin{array}{c}-5 \quad(-13 \text { to } 4) \\
p=0.26\end{array}$ & $\begin{array}{c}-14(-22 \text { to }-6) \\
p=0.001\end{array}$ \\
\hline
\end{tabular}

$\mathrm{Cl}=$ confidence interval, $\mathrm{cpKPI}=$ clinical pharmacy key performance indicator.

apercent difference was calculated as intervention group minus standard practice (control).

2-student model (block 1) relative to standard practice (mean difference $-0.4,95 \% \mathrm{CI}-1$ to $0 ; p=0.048)$. However, there was a successive increase in the number of DTPs resolved for the 3- and 4-student models (blocks 2 and 3). This trend can also be seen in Figure 2, which depicts the number of DTPs resolved, standardized to 20 pharmacist workdays.

The absolute total numbers of activities associated with cpKPIs 1, 2, 5, 6, and 7, standardized to 20 pharmacist workdays, for standard practice and blocks 1, 2, and 3 were 93, 75, 117 , and 135 , respectively (Figure 3 ). The pattern for these results was similar to that for number of DTPs resolved, with a reduction in productivity with the 2 -student model (block 1) and a subsequent trend toward increasing productivity when more learners were present (blocks 2 and 3).

Overall contributions by pharmacy students, pharmacy residents, and clinical pharmacists are visually depicted in

TABLE 7. Number of DTPs Resolved per Eligible Patient in Each Block, Relative to Standard Practice (Control)

\begin{tabular}{lcccc} 
Study Block & $\begin{array}{c}\text { No. of DTPs } \\
\text { Resolved } \\
\text { (Mean } \pm \text { SD) }\end{array}$ & $\begin{array}{c}\text { Mean Difference } \\
(95 \% \text { Cl) }\end{array}$ & $\boldsymbol{p}$ Value \\
\hline Control & $1.9 \pm 3.0$ & NA & NA \\
$\begin{array}{l}\text { Block } 1 \\
\text { (2 students) }\end{array}$ & $1.4 \pm 2.4$ & -0.4 & $(-1$ to 0$)$ & 0.048 \\
$\begin{array}{l}\text { Block 2 } \\
\text { (3 students) }\end{array}$ & $1.9 \pm 3.9$ & 0 & $(-0.6$ to 0.6$)$ & $>0.99$ \\
$\begin{array}{l}\text { Block 3 } \\
\text { (4 students) }\end{array}$ & $2.0 \pm 3.5$ & 0.08 & $(-0.4$ to 0.6$)$ & 0.7
\end{tabular}

$\mathrm{Cl}=$ confidence interval, DTP $=$ drug therapy problem, NA = not applicable, $\mathrm{SD}=$ standard deviation.
Figure 3. Overall, the pharmacists' productivity was reduced when learners were present relative to working alone, which is representative of the shared workload between pharmacists and learners and the increase in pharmacists' time spent performing preceptor activities.

\section{DISCUSSION}

The involvement of more pharmacy students in a structured LLPM appeared to improve clinical productivity as measured by cpKPIs. The absolute differences between proportions of eligible patients receiving cpKPI-related care suggest that overall clinical productivity was reduced with the 2 -student model but improved with the 4-student model.

These findings are also reflected in cpKPIs measured in terms of absolute numbers standardized to 20 pharmacist workdays. Using these standardized absolute numbers allows assessment of clinical productivity, regardless of the volume of patient admissions. Because more eligible patients would result in a smaller calculated proportion, the results for the 3 - and 4-student models would be conservative, as patient admissions were higher during these blocks (Table 4).

Two cpKPIs with significant improvements in the 4-student model relative to standard practice were provision of pharmaceutical care plans and provision of education during the hospital stay. Both activities are typically emphasized in pharmacy school and are high-yield learning opportunities for students, which may explain the positive correlation with the higher student models.

In addition to the theory that the presence of more students results in higher productivity, a possible confounder could be the clinical experience gained by learners as they progressed through rotations before entering the study. This 


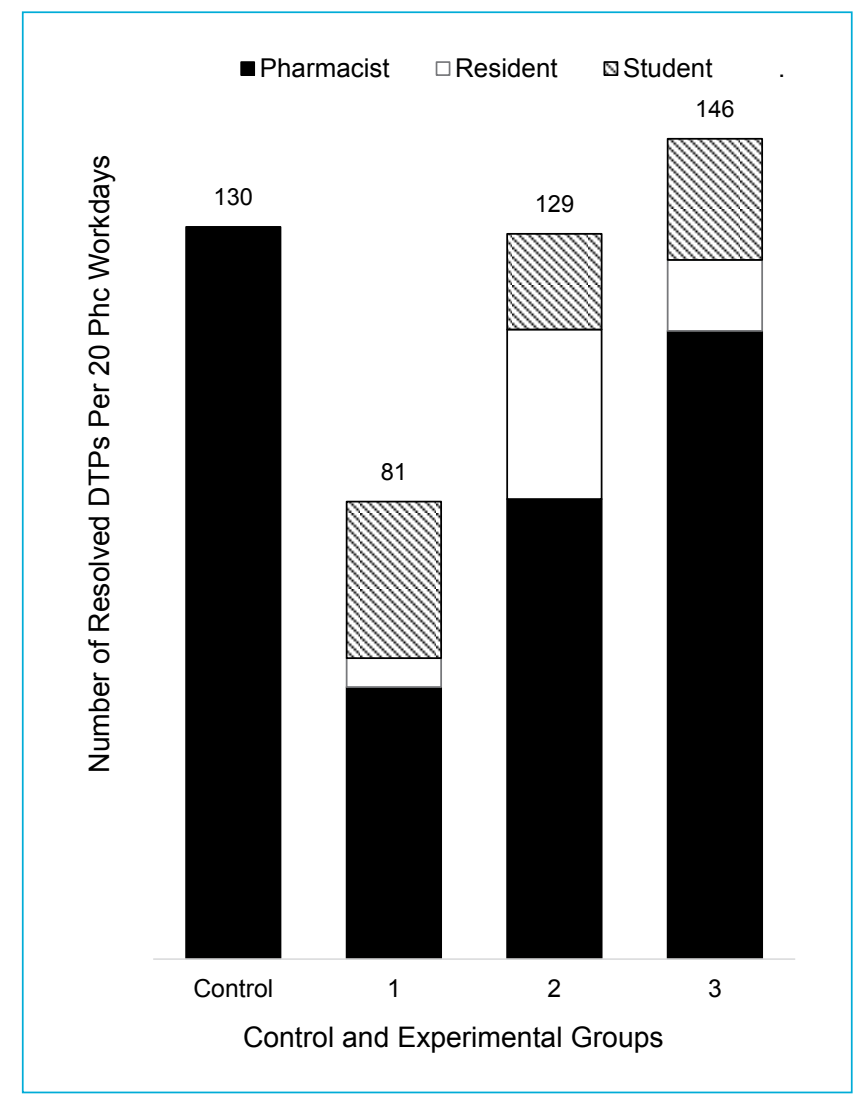

FIGURE 2. Total number of resolved drug-therapy problems (DTPs), standardized to 20 pharmacist (Phc) workdays, for each intervention group (block) and standard practice (control). The numbers 1, 2, and 3 designate blocks 1, 2, and 3, respectively, where blocks were distinguished by the number of PharmD students.

study also did not account for individual differences in student skill level or previous clinical or rotational experiences. Clinical efficiencies may also be gained through increased familiarity, experience, and comfort with the LLPM on the part of the pharmacist preceptors. Although this confounder was not formally accounted for, the pharmacists involved were experienced with the preceptor role within an LLPM and did not drastically modify their practice from one block to another.

The level of contributions by pharmacists while engaged in preceptor activities increased with the number of students, contrary to the popular belief that the presence of more students reduces the clinical productivity of pharmacists. One reason may be increased peer-learning time, as learners may initially be more likely to bring issues to each other than to the pharmacists. No trends in the contributions of residents were observed, as each LLPM involved only a single resident. Individual clinical proficiency and ability to manage first-time preceptor responsibilities may have resulted in highly variable data.

Yung and others ${ }^{14}$ found that the provision of discharge education and discharge medication reconciliation declined

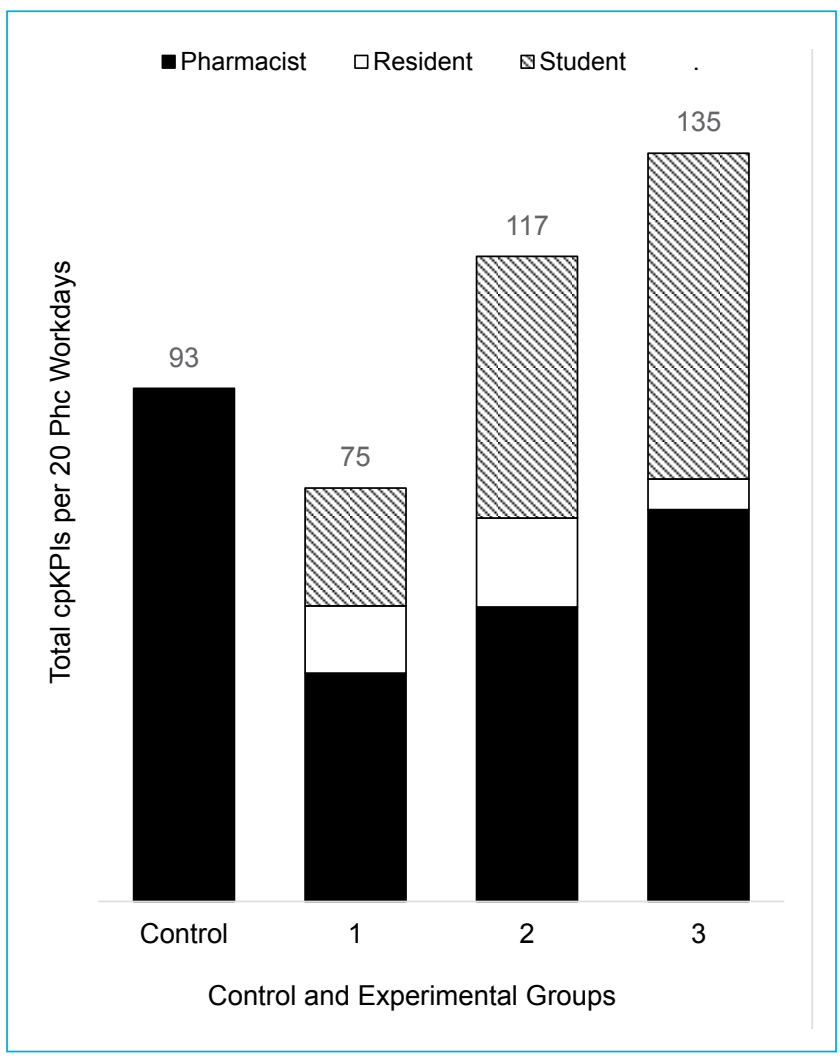

FIGURE 3. Total number of clinical pharmacy key performance indicators (cpKPIs), standardized to 20 pharmacist (Phc) workdays, for each intervention group (block) and standard practice (control). The numbers 1, 2, and 3 designate blocks 1, 2, and 3, respectively, where blocks were distinguished by the number of PharmD students.

when learners were present, most likely due to the timing of afternoon debriefing sessions. The role of medication safety facilitator at discharge was created to mitigate this reduction and to improve pharmacy-based care at discharge. The results indicated a trend toward an increase in the provision of education at discharge but a significant reduction in discharge medication reconciliation relative to standard practice. This may reflect the fact that discharge medication reconciliation can be completed remotely, whereas education at discharge requires an in-person meeting with the patient, which can be difficult to coordinate as the patient prepares to leave the hospital. Introduction of the role of medication safety facilitator at discharge presumably facilitated coordination of discharge counselling sessions, in addition to having a pharmacy team member with available time dedicated to the activity, thus improving education at discharge compared with standard practice.

Conducting a proper assessment of trends in discharge-related activities is challenging. Discharges may occur outside of rotation practice hours during the daytime, and such discharges were not recorded in our study. For example, if a higher number of discharges occurred during student 
hours during block 3, this LLPM would appear to have more instances of education at discharge and discharge medication reconciliation. The patients who died during their respective admissions were not considered eligible for discharge-related activities and were censored from assessment of the corresponding cpKPIs. However, patients who were transferred to another institution and palliative patients being discharged for end-of-life care were not routinely eligible for discharge activities provided by pharmacy learners, and education at discharge and discharge medication reconciliation outcomes were not routinely censored for these patients.

One limitation of this study was the dependence of data collection on physical recording of cpKPIs. Electronic recording of cpKPIs might increase the accuracy of results. Consequently, a potential confounder could be the improved consistency of cpKPI recording by the 2 FTE pharmacists as the study progressed. In addition, the teaching and mentoring time of pharmacists and residents was not adequately recorded; therefore, any potential differences in preceptor time requirements across the 3 blocks cannot be described. Preceptor time outside of the expected work hours was also not captured, but this was not thought to be significantly different across blocks, and preceptors made an effort to finish daily duties on time. Variations in overlap of learners were not reliably recorded. Additionally, 1 student was present for an extra week in the 2-student model, providing a potential productivity advantage. Although this might have affected the magnitude of effect, a meaningful impact on the results is unlikely.

The findings of this study suggest an increase in cpKPI performance with a greater number of learners. However, it is unknown whether cpKPI-related activities performed by learners are equivalent in quality to those performed by pharmacists. Previous studies have demonstrated that clinical pharmacist activities are associated with outcomes such as reductions in hospital length of stay, mortality, adverse drug reactions, health care costs, and readmissions. ${ }^{16-18}$ Learners are under the supervision of a pharmacist and are taught to practise as a fully qualified pharmacist would, which is facilitated by a smaller patient load. One study showed that implementation of a pharmacy LLPM resulted in improved patient satisfaction scores. ${ }^{9}$ Pharmacy learners may arguably be more meticulous in their patient care plans, given that their performance is being assessed.

Two important considerations for studies involving experiential learning rotations are the learners' satisfaction with their experience and the quality of their education. In their qualitative study, Bates and others ${ }^{5}$ assessed perceptions of learners practising within an LLPM. Residents described development of their time management skills through the balancing of clinical and preceptorship activities, and assessments demonstrated that learning outcomes were met. The students also reported a preference for practising directly under a resident, given the recency of the latter's student experience, ${ }^{5}$ a preference that was echoed in a Canadian study evaluating the experience of pharmacy students practising within an LLPM. ${ }^{19}$

Although the current study focused on the impact of an LLPM on clinical productivity, future studies could include participant satisfaction surveys for both learners and preceptors and an evaluation of the learning outcomes achieved, to ensure the delivery of a high-quality educational rotation.

\section{CONCLUSION}

Implementation of an LLPM involving pharmacists, a resident, and 3 or 4 pharmacy students on an inpatient oncology unit appeared to improve clinical productivity relative to standard practice, as measured by cpKPIs. Although this study had several limitations, it is the first of its kind, and the results will be valuable in structuring pharmacy experiential learning rotations and will provide a platform for future research.

\section{References}

1. Accreditation standards for Canadian first professional degree in pharmacy programs. Canadian Council for Accreditation of Pharmacy Programs; 2018 [cited 2018 Oct 31]. 31 pp. Available from: https:// ccapp.ca/wp-content/uploads/2020/10/July7-CCAPP-Professional -Standards-ENG.pdf

2. Danielson J, Craddick K, Eccles D, Kwasnik A, O'Sullivan TA. A qualitative analysis of common concerns about challenges facing pharmacy experiential education programs. Am J Pharm Educ. 2015;79(1):1-8.

3. Loy BM, Yang S, Moss JM, Kemp DW, Brown JN. Application of the layered learning practice model in an academic medical center. Hosp Pharm. 2017;52(4):266-72.

4. Pinelli NR, Eckel SR, Vu MB, Weinberger M, Roth MT. The layered learning practice model: lessons learned from implementation. Am J Health Syst Pharm. 2016;73(24):2077-82.

5. Bates JS, Buie LW, Lyons K, Rao K, Pinelli NR, McLaughlin JE, et al. A study of layered learning in oncology. Am J Pharm Educ. 2016;80(4):68.

6. Raman-Wilms L. Marriage of individual pharmacists' achievement on key performance indicators and teaching responsibilities [editorial]. Can J Hosp Pharm. 2014;67(2):97-8.

7. Bates JS, Buie LW, Amerine LB, Savage SW, Eckel SR, Patel R, et al. Expanding care through a layered learning practice model. Am J Health Syst Pharm. 2016;73(22):1869-75.

8. Delgado O, Kernan WP, Knoer SJ. Advancing the pharmacy practice model in a community teaching hospital by expanding student rotations. Am J Health Syst Pharm. 2014;71(21):1871-6.

9. Soric MM, Glowczewski JE, Lerman RM. Economic and patient satisfaction outcomes of a layered learning model in a small community hospital. Am J Health Syst Pharm. 2016;73(7):456-62.

10. Fernandes O, Toombs K, Pereira T, Lyder C, Bjelajac Mejia A, Shalansky S, et al. Canadian consensus on clinical pharmacy key performance indicators: knowledge mobilization guide. Canadian Society of Hospital Pharmacists; 2015.

11. Gorman S, Slavik R. Should key performance indicators be a component of performance assessment for individual clinical pharmacists? The "pro" side. Can J Hosp Pharm. 2014;67(2):165-6.

12. Fernandes OA, Le Piane F, Ahmed H, Toombs K. Should key performance indicators be a component of performance assessment for individual clinical pharmacists? The "con" side. Can J Hosp Pharm. 2014;67(2):166-8.

13. Fernandes O, Gorman SK, Slavik RS, Semchuk WM, Shalansky S, Bussières JF, et al. Development of clinical pharmacy key performance indicators for hospital pharmacists using a modified Delphi approach. Ann Pharmacother. 2015;49(6):656-69. 
14. Yung J, Nguyen T, MacLean R, Wentzell J. Assessing the impact of a layered learning practice model on the delivery of clinical pharmacy key performance indicators within an oncology unit of a tertiary care centre. Can J Hosp Pharm. 2019;72(3):202-10.

15. Hospital to home - facilitating medication safety at transitions: a toolkit and checklist for healthcare providers. Institute for Safe Medication Practices Canada; 2015 [cited 2018 Nov 25]. Available from: https://www.ismp-canada.org/transitions/

16. Bond CA, Raehl CL. Clinical pharmacy services, pharmacy staffing, and adverse drug reactions in United States hospitals. Pharmacotherapy. 2006;26(6):735-47.

17. Gillespie U, Alassaad A, Henrohn D, Garmo H, Hammarlund-Udenaes $\mathrm{M}$, Toss $\mathrm{H}$, et al. A comprehensive pharmacist intervention to reduce morbidity in patients 80 years or older: a randomized controlled trial. Arch Intern Med. 2009;169(9):894-900.

18. Makowsky MJ, Koshman SL, Midodzi WK, Tsuyuki RT. Capturing outcomes of clinical activities performed by a rounding pharmacist practicing in a team environment: the COLLABORATE study. Med Care. 2009;47(6):642-50

19. Tsang L, Le MH, Teo V, Hardy B. Evaluation of a new hierarchical teaching model for pharmacy students in experiential education. Can J Hosp Pharm. 2013;66(3):184-9.
Lauren (Ellie) Salsbury, BSc(Hons), BScPhm, ACPR, was, at the time of this study, with The Ottawa Hospital, Ottawa, Ontario. She is now with the Nova Scotia Health Authority, Halifax, Nova Scotia.

Stephanie Lovering, BSc(Hons), BScPhm, PharmD, ACPR, is with The Ottawa Hospital, Ottawa, Ontario.

Tiffany Nguyen, BSCPhm, ACPR, BCOP, is with The Ottawa Hospital and the Ottawa Hospital Research Institute, Ottawa, Ontario.

Jason Yung, BMSc, PharmD, ACPR is with the University Health Network, Toronto, Ontario.

Jason Wentzell, BScPhm(Hons), ACPR, BCOP, MHM, is with the Ottawa Hospital Research Institute, and Extend Pharmacy, Ottawa, Ontario, and the School of Pharmacy, University of Waterloo, Kitchener, Ontario.

Competing interests: Jason Wentzell serves as Regional Clinical Coordinator for the PharmD program in the School of Pharmacy, University of Waterloo. No other competing interests were declared.

\section{Address correspondence to: \\ Lauren (Ellie) Salsbury \\ Pharmacy Department \\ Dartmouth General Hospital \\ 325 Pleasant Street \\ Dartmouth NS B2Y 4G8 \\ email: lesalsbury@gmail.com \\ Funding: None received.}

Acknowledgements: The authors would like to thank the pharmacy residents and students who participated in this research study during their educational rotations, without whom the project would not have been possible. 